\title{
Table Correction: Using Technology to Facilitate Fidelity Assessments: The Tele-STAR Caregiver Intervention
}

\author{
Allison Lindauer ${ }^{1 *}, \mathrm{PhD}, \mathrm{NP}$; Glenise McKenzie ${ }^{2 *}, \mathrm{PhD}, \mathrm{RN}$; David LaFazia, ${ }^{3,4^{*}}, \mathrm{PhD}, \mathrm{MSW}$; Loriann McNeill ${ }^{5 *}, \mathrm{BS}$; \\ Kate Mincks $^{1 *}$, BA; Natasha Spoden ${ }^{1 *}$, MS; Marcella Myers ${ }^{1 *}$, LPN; Nora Mattek ${ }^{1 *}$, MPH; Linda L Teri ${ }^{4,6^{*}}$, PhD \\ ${ }^{1}$ Layton Aging and Alzheimer's Disease Center, Oregon Health \& Science University, Portland, OR, United States \\ ${ }^{2}$ School of Nursing, Oregon Health \& Science University, Portland, OR, United States \\ ${ }^{3}$ School of Social Work, University of Washington, Seattle, WA, United States \\ ${ }^{4}$ Northwest Research Group on Aging, School of Nursing, University of Washington, Seattle, WA, United States \\ ${ }^{5}$ Family Caregiver Support Program, Multnomah County, Oregon, Portland, OR, United States \\ ${ }^{6}$ Northwest Roybal Center, School of Nursing, University of Washington, Seattle, WA, United States \\ *all authors contributed equally
}

\section{Corresponding Author:}

Allison Lindauer, $\mathrm{PhD}, \mathrm{NP}$

Layton Aging and Alzheimer's Disease Center

Oregon Health \& Science University

3181 SW Sam Jackson Park Road, CR-131

Portland, OR, 97239

United States

Phone: 15034944347

Fax: 15034947499

Email: lindauer@ohsu.edu

\section{Related Article:}

Correction of: https://www.jmir.org/2019/5/e13599/

(J Med Internet Res 2020;22(4):e18032) doi: 10.2196/18032

In the original published paper "Using Technology to Facilitate Fidelity Assessments: The Tele-STAR Caregiver Intervention" (J Med Internet Res 2019; 21(5):e13599), the authors noticed an error in Table 5. This was caused by a coding error on the authors' electronic survey. The original table listed the 10-item Center for Epidemiological Studies Depression Scale (CESD-10) score for the time point "Post session 4" lower than it should have been.

The score was initially listed as:

Mean 9.4, SD 6.8 (row 1, column 3), $P=.84$ (row 1 , column 5).
The correct score is:

Mean 11.1, SD 4.7 (row 1, column 3), $P=.88$ (row 1, column 5).

The changes were not significant, and do not affect the overall findings of the paper.

The correction will appear in the online version of the paper on the JMIR website on April 28, 2020, together with the publication of this correction notice. Because this was made after submission to PubMed, PubMed Central, and other full-text repositories, the corrected article has also been resubmitted to those repositories.

This is a non-peer-reviewed article. Submitted 29.01.20; accepted 17.02.20; published 28.04.20.

Please cite as:

Lindauer A, McKenzie G, LaFazia D, McNeill L, Mincks K, Spoden N, Myers M, Mattek N, Teri LL

Table Correction: Using Technology to Facilitate Fidelity Assessments: The Tele-STAR Caregiver Intervention

J Med Internet Res 2020;22(4):e18032

URL: https://www.jmir.org/2020/4/e18032

doi: $10.2196 / 18032$

PMID: 32343671 
(C)Allison Lindauer, Glenise McKenzie, David LaFazia, Loriann McNeill, Kate Mincks, Natasha Spoden, Marcella Myers, Nora Mattek, Linda L Teri. Originally published in the Journal of Medical Internet Research (http://www.jmir.org), 28.04.2020. This is an open-access article distributed under the terms of the Creative Commons Attribution License (https://creativecommons.org/licenses/by/4.0/), which permits unrestricted use, distribution, and reproduction in any medium, provided the original work, first published in the Journal of Medical Internet Research, is properly cited. The complete bibliographic information, a link to the original publication on http://www.jmir.org/, as well as this copyright and license information must be included. 